\title{
Universidades e a produção de patentes: tópicos de interesse para o estudioso da informação tecnológica
}

Suzana Pinheiro Machado Mueller

\author{
Professora Colaboradora do Programa de Pós \\ Graduação em Ciência da Informação \\ Universidade de Brasília
}

Valmira Perucchi

Bibliotecária do Instituto Federal de Educação, Ciência e Tecnologia da Paraíba.Doutoranda em Ciência da Informação pela Universidade de Brasília

http://dx.doi.org/10.1590/1981-5344/1828

Com base na literatura de várias áreas, discorre sobre três questões potencialmente influentes no estudo da patente universitária, sob a ótica da ciência da informação: o pesquisador/inventor acadêmico e seu dilema, patentear ou publicar; universidades como produtoras de patentes e a concentração geográfica das instituições mais capazes; e gestão e comercialização das patentes universitárias. $O$ texto termina com considerações sobre a complexidade do tema como objeto de estudo e o potencial que apresenta para pesquisas e serviços na área de informação.

Palavras-Chave: Patentes universitárias - Brasil; Núcleos de Inovação Tecnológica em universidades brasileiras; Comunicação tecnológica - patentes universitárias, Brasil; Inovação tecnológica; Gestão de patentes.

\section{Universities and patent production: issues for the study of technological information}

Based on the literature from various areas, it presents three topics considered relevant to university patents as an object of study to information scientists: the academic researcher as an inventor and his dilemma between 
patenting and publishing; Brazilian universities as producers of innovation and their geographic distribution; university problems in managing and commercializing patents. It ends with considerations about the complexity of the subject as an object of study and its potential as a topic for research for information scholars.

\begin{abstract}
Keywords: University patents - Brazil; Nucleus of Tecnhnological Innovation in Brazilian universities; Technological communication - university patents, Brazil. Technological innovation; Patents management.
\end{abstract}

Recebido em 11.06.2013 Aceito em 21.11.2013

\title{
1 Introdução
}

A expressão ciência e tecnologia e inovação, comumente abreviada para CT\&I, reflete a interação e a interdependência entre essas áreas. Pela sua natureza, o conhecimento científico, tecnológico e a inovação dependem da comunicação, e a comunicação desses conhecimentos é objeto de estudo da ciência da informação. Mas a atenção dos estudiosos da ciência da informação à comunicação da ciência e à comunicação da tecnologia tem se mostrado bastante desigual.

Artigos científicos e patentes são, respectivamente, meios de divulgação de conhecimento científico e tecnológico. Há vários pontos em comum entre esses dois documentos, tais como a necessidade de validação por avaliadores e o de serem meios de registro de autoria ou propriedade do conhecimento. Mas há duas diferenças fundamentais: o direito à propriedade e o direito de acesso e uso. A propriedade intelectual do conhecimento científico é sempre de seu autor e inalienável. Sua divulgação se dá por meio de artigos referendados publicados em revistas científicas e, embora muitas dessas revistas ainda sejam acessíveis apenas por meio de assinatura ou compra e o artigo passe a ser propriedade da editora, o conhecimento contido nesses artigos pode ser livremente utilizado, desde que corretamente citado. As patentes, por outro lado, são obtidas mediante depósito do documento, contendo a descrição da invenção a ser patenteada nas instituições capacitadas para tal. A propriedade (ou direito) sobre os conteúdos é concedida a quem a deposita, não necessariamente ao autor, e seu uso por terceiros envolve pagamentos ao detentor dos direitos sobre a patente.

A comunicação do conhecimento científico é uma área tradicional de interesse dos estudiosos da área da ciência da informação. Existe farta literatura internacional e nacional sobre os muitos aspectos do tema. Boa parte dessa literatura se refere aos periódicos e artigos científicos, mas todos os veículos e formas de comunicação têm sido estudados, bem como a complexa rede de atores envolvidos no processo, suas práticas e crenças. Há estudos que privilegiam aspectos sociais da comunicação 
científica, apoiando-se, em geral, em fundamentação teórica oriunda das ciências sociais, e um corpo significativo de estudos quantitativos da produção e comunicação científica com o uso da bibliometria e cientometria, estudo de redes e outras técnicas, com base na matemática e estatística. Como resultado, os fatores que agem sobre a comunicação científica e sobre o contexto no qual ela é produzida e circula, especialmente nos ambientes acadêmicos, são conhecidos, proporcionando base para o avanço contínuo do conhecimento.

A literatura publicada por autores da ciência da informação sobre a comunicação do conhecimento tecnológico e a inovação é bem menor que sobre o conhecimento científico, embora, por sua natureza, seja igualmente central aos interesses da área. Mas, desde a aprovação da Lei da o 9.279, de 1996 (BRASIL, 1996), que regula direitos e obrigações relativos à propriedade industrial, o número de artigos e teses sobre patentes, que privilegiam a ótica da informação, vem crescendo, formando um conjunto ainda pequeno, mas promissor sobre patentes em geral e sua produção. Este estudo pretende se somar a essa literatura crescente. Limita-se às patentes universitárias, expondo algumas das questões presentes no contexto acadêmico que influenciam inventores e suas universidades. A motivação parte do pressuposto que é necessário aos pesquisadores da ciência da informação, interessados na comunicação do conhecimento tecnológico e inovação, conhecerem os fatores e as questões que influenciam o contexto da produção da patente, da mesma forma que é necessário aos pesquisadores da ciência da informação, interessados na comunicação do conhecimento científico, conhecerem o contexto da produção artigos.

Este texto está organizado em cinco seções. Após esta introdução, descrevem-se os procedimentos que explicam como os textos pertinentes foram selecionados. Segue-se uma breve seção sobre patentes em geral. Depois, vem a seção principal, sobre patentes universitárias, que está dividida em três subseções. Na seção final, são feitos comentários gerais sobre o tema e seu potencial como contribuição às pesquisas na área de informação.

\section{Procedimentos}

A pergunta orientadora deste levantamento de literatura foi: considerando as patentes universitárias como veículo de informação do conhecimento tecnológico e aplicado e, como tal, objeto de estudo do pesquisador da área da informação, quais fenômenos e questões esse pesquisador precisa considerar, de forma a melhor entender seu objeto de estudo? Pareceu necessário, primeiramente, reunir informações sobre patentes em geral. Um pouco de história, a autoridade legal, leis e conceitos e o sistema de classificação foram os temas que logo se apresentaram como os mais relevantes. Esses tópicos não foram explorados em profundidade, foram coletadas informações apenas suficientes para fornecer o pano de fundo contra o qual o tema deste trabalho pudesse ser desenvolvido. A seguir, textos sobre patentes 
universitárias foram identificados e seus conteúdos explorados em busca de questões recorrentes e relevantes. Surgiram vários tópicos igualmente importantes, mas, devido às limitações de espaço em um artigo, apenas três foram selecionados. Embora inter-relacionados, foram considerados separadamente para fins de exposição: fatores que agem sobre o inventor/pesquisador em sua decisão sobre patentear; a universidade como produtora de patentes; e a gestão e comercialização da patente pela universidade. Esses três tópicos formaram a estrutura da parte principal do trabalho.

A busca dos textos seguiu o método descrito por Hanson (1975) como bola de neve, mas, como em toda busca na literatura, também houve um pouco de serendipity: uma busca inicial no Google e Google acadêmico, por meio da palavra-chave patentes em universidades no Brasil recuperou três artigos relativamente recentes, Amadei e Torkomian (2009), Oliveira e Velho (2009a) e Serafini et al. (2011). Nesses textos, foram identificadas questões que levaram a outros textos e a outras questões, provocando a busca por mais informação. Os textos foram recuperados em várias fontes e bases de dados, tais como Portal de Periódicos da Capes, Biblioteca Digital de Teses e Dissertações (BDTD) do Instituto Brasileiro de Informação em Ciência e Tecnologia (IBICT) e catálogos digitais de bibliotecas de universidades públicas estaduais e federais. Não houve limite quanto à área ou tipo de publicação que originou o texto, à formação do autor ou sua atuação como pesquisador acadêmico ou profissional praticante. Os textos que foram reunidos têm em comum o interesse por questões relacionadas à produção e gestão de patentes universitárias $\mathrm{e}$, entre eles, há artigos de periódicos referendados, teses, sites oficiais e comerciais de organizações dedicadas a patentes, além de revistas especializadas não científicas. 0 levantamento não se limitou à literatura nacional, mas foi feito um esforço para identificar textos brasileiros sobre o assunto. Não se pretendeu um levantamento exaustivo, mas informativo dos tópicos selecionados.

\section{Sobre patentes em geral}

França (2000, p. 163) discorre sobre vários aspectos relacionados ao conceito e à prática do depósito e uso de patentes, inclusive um pouco da história do sistema de patentes. Esclarece que as inovações registradas nas patentes têm potencialmente valor comercial e são, por isso, protegidas por legislação específica. Cada país tem a sua própria legislação, mas há um conjunto de princípios básicos estabelecidos na Convenção da União de Paris, em 1883, que propicia alguma padronização e, portanto, convivência entre os países signatários. França descreve em seu texto a participação da Organização das Nações Unidas (ONU) e de um de seus organismos, Organização Mundial de Propriedade Intelectual (OMPI), na intermediação de questões, com base no Tratado de Cooperação sobre Patentes (TCP), assinado em 1970.

No Brasil, a Lei No 9.279, de 14 de Maio de 1996 (BRASIL, 1996), regula direitos e obrigações relativos à propriedade industrial. O órgão 
encarregado pela sua aplicação é Instituto Nacional da Propriedade Industrial (INPI), criado em 1970, hoje uma autarquia federal vinculada ao Ministério do Desenvolvimento, Indústria e Comércio Exterior (MDIC). De acordo com informações em seu site, o INPI

é responsável pelo aperfeiçoamento, disseminação e gestão do sistema brasileiro de concessão e garantia de direitos de propriedade intelectual para a indústria. Entre [seus] serviços, estão os registros de marcas, desenhos industriais, indicações geográficas, programas de computador e topografias de circuitos, as concessões de patentes e as averbações de contratos de franquia e das distintas modalidades de transferência de tecnologia (INPI, 2012).

De acordo com o INPI (2013), "patente é um título de propriedade temporária sobre uma invenção ou modelo de utilidade, outorgado pelo Estado aos inventores ou autores ou outras pessoas físicas ou jurídicas detentoras de direitos sobre a criação". Como condição para a concessão dos direitos sobre a patente, o INPI exige que 0 inventor revele "detalhadamente todo o conteúdo técnico da matéria protegida pela patente". O INPI descreve dois tipos de patentes, a patente de invenção, cujo prazo de validade é de 20 anos e o modelo de utilidade, com validade de 15 anos: patentes de invenção são "produtos ou processos que atendam aos requisitos de atividade inventiva, novidade e aplicação industrial" e modelo de utilidade é "objeto de uso prático, ou parte deste, suscetível de aplicação industrial, que apresente nova forma ou disposição, envolvendo ato inventivo, que resulte em melhoria funcional no seu uso ou em sua fabricação". O INPI complementa informando que "não se pode patentear um processo como Modelo de Utilidade, somente como Patente de Invenção" (INPI, 2013).

A patente só é concedida pelo INPI depois de examinada por seus peritos, os quais, entre outros pontos, se certificam de que a solicitação atende ao que dispõe a Lei 9.279/96: "Art. 80. É patenteável a invenção que atenda aos requisitos de novidade, atividade inventiva e aplicação industrial" (BRASIL, 1996).

O conceito de atividade inventiva é esclarecido um pouco mais adiante, na mesma Lei: "Art. 13. A invenção é dotada de atividade inventiva sempre que, para um técnico no assunto, não decorra de maneira evidente ou óbvia do estado da técnica" (BRASIL, 1996).

Dos três requisitos estabelecidos para concessão de patentes de invenção nomeados no Art. $8^{\circ}$, o quesito novidade tem influência direta na comunicação científica e tecnológica. A Agência USP de Inovação (2013) deixa claro essa implicação:

Novidade: significa que a invenção é algo novo, "não compreendido no estado da técnica", expressão que abrange todas as publicações e outros meios acessíveis ao público antes da data de depósito do pedido de patente, por descrição escrita ou oral, por uso ou qualquer outro meio, no 
Brasil ou no exterior, incluindo-se defesas de tese, dissertação, apresentação de pôsteres, painéis, entrevistas, artigos científicos, entre outros.

A Agência USP de Inovação (2013) deixa ainda claro que o pesquisador inventor não pode publicar nada antes de registrar o pedido de patente, de maneira a manter o sigilo necessário para atender ao requisito novidade.

A carta patente, ou simplesmente patente, é o documento que formaliza a concessão dos direitos sobre a invenção ou modelo. É concedida depois do exame e aprovação do pedido, pelos técnicos do INPI. A concessão é feita a quem a solicitou, não necessariamente ao inventor. O detentor da patente tem direitos de propriedade sobre 0 conhecimento patenteado e pode cobrar de terceiros interessados em seu uso.

Duas leis mais recentes foram promulgadas com o objetivo de complementar a Lei 9.279/96 e estimular a geração de patentes, inclusive em universidades: a chamada Lei da Inovação - Lei no. 10.973, de 2004 (BRASIL, 2004), que "visa estimular a interação das universidades com o setor produtivo sendo que para isso as universidades precisam se adequar às novas exigências que incluem, entre outras ações, a criação de Núcleos de Inovação Tecnológica" (GUARNICA; OLIVEIRA; TOMARKIAN, 2006), e a Lei do Bem, Lei no. 11.196, de 2005, que concede incentivos a todas as empresas que aplicam em inovação. Mas, apesar dessas novas leis, há muitas críticas ao sistema brasileiro de patentes, especialmente em relação ao excesso de burocracia e à demora entre depósito e concessão. Também há críticas ao sistema judiciário, pela sua lentidão em relação ao sistema de patentes (LAMANA; KOVALESKI, 2010; THIMOTEO, 2013).

Seria impossível identificar, organizar e recuperar as patentes sem algum sistema de classificação, pois o volume de patentes registradas tende a crescer e não há limites aos temas ou assuntos a que se referem. O sistema usado no Brasil ${ }^{1}$ e por muitos outros países é conhecido como Classificação Internacional de Patente (CIP). Esse sistema foi formado com a colaboração de vários países, com base em tratado internacional celebrado em 1954, a Convenção Europeia para a Classificação Internacional de Patentes de Invenções (GRUPO MERCOSUL MARCAS E PATENTES, 1995-2005). Com base no texto desse tratado, um novo acordo sob o patrocínio da OMPI foi proposto, resultando no Acordo de Estrasburgo Relativo à Classificação Internacional de Patentes, celebrado em 1971, mas que entrou em vigor em 1975. Apesar de ter origem em consenso entre países e de passar por atualizações periódicas, a CIP, como ficou conhecida, sofre críticas quanto a sua clareza e adequação (JANNUZZI; AMORIM; SOUZA, 2007). A última versão data de 2013 e está disponível em inglês, versão digital (INTERNATIONAL PATENT CLASSIFICATION GUIDE, 2013). A 7a versão, datada de 1999, está

1 Veja Diário Oficial da União de 20/09/1974 (retificação da publicação do Diário Oficial da União de 03/09/74), que "Aprova o texto do acordo de Estrasburgo relativo à classificação internacional de patentes, firmado em Estrasburgo, a 24 de março de 1971". 
traduzida para o português e também disponível online ${ }^{2}$. É uma classificação hierárquica, composta de Seção, Classe, Subclasse e Grupo. No nível mais alto, existem oito seções, representadas pelas letras de $A$ a $\mathrm{H}$; cada seção é dividida em classes, cada classe em subclasses e cada subclasse em grupos, que podem conter subgrupos. As oito classes, primeiro nível hierárquico, são: A - Necessidades humanas; B Operações de processamento, transportes; C - Química; Metalurgia; D Têxteis; Papel; E - Construções fixas; F - Engenharia mecânica; Iluminação; Aquecimento; Armas; Explosões; $\mathrm{G}$ - Física; e H Eletricidade.

As patentes universitárias são tratadas da mesma maneira que qualquer outra patente pelo INPI. Mas, para o estudioso da ciência da informação interessado na patente como um veículo de informação, é imprescindível levar em conta o complexo contexto de origem dessas patentes. Esse é o cenário em que se encaixa este artigo.

\section{Patentes universitárias}

Conforme especificado na seção sobre procedimentos, a apresentação dos tópicos identificados no contexto da geração e gestão da patente universitária, considerados relevantes ao pesquisador da informação, é feita em três subseções: a primeira se relaciona com o pesquisador/inventor e alguns dilemas que enfrenta; a segunda com a universidade como produtora de patentes; e a terceira com a gestão e comercialização da patente pelas universidades.

\subsection{0 pesquisador/inventor}

A expressão patentes universitárias tem sido usada na literatura para designar patentes geradas em universidades ou com a participação de universidades. A produção de patentes como resultado de pesquisas acadêmicas, no entanto, é um tema polêmico que envolve pelo menos duas questões. A primeira diz respeito ao papel da universidade e de cientistas acadêmicos na produção de conhecimento dirigido à utilização (não ao entendimento), isto é, de tecnologias aplicáveis à solução de problemas sociais. A segunda envolve conceitos subjetivos relacionados à ética, ao esforço pela visibilidade acadêmica e a questões suscitadas pelo ganho privado advindo de pesquisa financiada com verbas públicas ou desenvolvida em universidades públicas. Ambas serão discutidas a seguir.

A primeira questão tem como ponto central a concepção de ciência e a noção de objetivos legítimos para a pesquisa acadêmica. Na explicação de Stokes (2005), durante quase todo o Século XX, prevaleceu a ideia de que a ciência pura e a ciência aplicada e tecnologia seriam extremos antagônicos de um contínuo, no sentido em que a função dos pesquisadores é exclusivamente avançar nosso entendimento da natureza e da sociedade, sem preocupações com usos práticos desse

Disponível nos sites da OMPI: <http://www.wipo.int/classifications/ipc/en> e do INPI em <http://www.inpi.gov.br>. Acesso: em 7 mar. 2012. 
conhecimento. Do outro lado do contínuo, a ciência aplicada e tecnologia seriam consequências da ciência pura, que haveria um fluxo de conhecimento puro para fundamentar e inspirar inovações práticas. Stokes (2005) atribui a Vannevar Bush, influente diretor do Escritório de Pesquisa e Desenvolvimento Científico dos Estados Unidos (U.S. Office of Scientific Research and Development) durante a Segunda Grande Guerra, não apenas a origem mas "o alicerce da política científica [americana] para as décadas posteriores à guerra". Stokes (2005) discorda dessa concepção, à qual se refere como o "paradigma do pós-guerra" (p.133), argumentando que, historicamente, muitos cientistas desenvolveram ciência pura e também ciência aplicada. Embora admita que talvez ainda persista em algumas comunidades científicas, acredita, como Rosenberg (1991, citado por STOKES 2005, p. 133), "que todos sabem que o modelo linear está morto". Continua Stokes, sobre o modelo linear:

Ele sofreu ferimentos mortais causados pela percepção disseminada do quanto são múltiplas, complexas e desigualmente percorridas as trajetórias entre o progresso científico e o tecnológico; de quão frequentemente a tecnologia serve de inspiração à ciência, em vez de ocorrer o contrário; e de quantas melhorias da tecnologia nem sequer esperam pela ciência (STOKES, 2005, p. 133).

Desde as últimas décadas do Século $X X$, essa visão mais pragmática e realista da ciência vem sendo adotada por agências nacionais de fomento, em todo o mundo. Hoje, prevalece a ideia que não apenas é viável, mas necessário que cientistas desenvolvam ciência pura e assumam ao mesmo tempo responsabilidade pela aplicação dos conhecimentos. Várias universidades americanas e europeias assumiram a incumbência de apoiar pesquisadores no processo de patenteamento. No Brasil, a promulgação de leis que facilitam a interação entre universidade e indústria atesta a mudança de atitude também em nosso país.

A segunda questão é mais complexa, porque envolve decisões individuais de cada cientista. O patenteamento dos resultados de pesquisas financiadas por verba pública ou realizadas em universidades públicas é um tema controvertido, apontado por vários autores ${ }^{3}$ como um dilema ético para o cientista. Póvoa (2010, p. 232) discute essa questão, deixando claro o problema: "patentear invenções financiadas por recursos públicos parece ser uma contradição, afinal, os contribuintes já estão pagando para que conhecimentos sejam criados e gerem benefícios para a sociedade". Outra faceta desse mesmo dilema enfrentado pelo pesquisador envolve a busca pela visibilidade e prestígio acadêmico que adviria de um artigo aceito em revista referendada tão prestigiada quanto possível e publicado tão logo quanto possível. Caso a decisão seja pela patente, o que garante propriedade ao inventor sobre suas descobertas, a

\footnotetext{
${ }^{3}$ Assunto tratado tanto em boletins dedicados a cientistas, como Science Careers ou Times Higher Education quanto em artigos em revistas referendadas, como, por exemplo, McMillan et al. (2006).
} 
publicação como artigo terá que esperar, pois patentear exige sigilo durante todo o processo de análise que antecede a sua concessão e esse período é longo. O pesquisador deve considerar as vantagens e desvantagens não apenas para ele e sua carreira, mas, também, para a sua instituição e para a sociedade. Conforme mencionado por Póvoa (2010) e também por Oliveira e Velho (2009a; 2009b), a decisão por patentear pode provocar, ainda, outro problema de natureza ética, pois iria contra duas normas do ethos científico proposto por Merton, o desinteresse e o compartilhamento. A norma do desinteresse proibiria o cientista de buscar ganhos financeiros com suas pesquisas e 0 comunalismo estabelece a ciência como conhecimento público, aberto a críticas.

Póvoa (2010, p. 236-237) argumenta, ainda, que "existem chances de que vários progressos científicos possam ser afetados pela dificuldade de acesso à informação imposta por alguma patente". Por exemplo,

alguns aspectos da cultura das universidades, como a divulgação rápida dos resultados, [que] podem ser afetados se o pesquisador preferir retardar a publicação até realizar o pedido da patente. De fato, algumas defesas de tese de doutorado estão deixando de ter seu caráter de ato público para se realizarem "a portas fechadas" e com compromisso escrito dos membros da banca examinadora de não divulgar os resultados a que tiverem acesso (POVOA, 2010, p. 242).

Apesar das controvérsias, a posição favorável ao patenteamento parece estar cada vez mais difundida entre os pesquisadores, universidades e a sociedade em geral. Nas palavras de Póvoa (2010, p. 252): "o problema passa a ser "como" a universidade deve patentear e não "se deve" patentear". Federman (2009), examinadora de patentes do INPI, reforça a decisão pelo patenteamento:

0 que 0 inventor deve fazer? Mais especificamente, o que o pesquisador de centros de pesquisa e universidades deve fazer? Publicar artigos? Depositar a patente? [...]. É notório que o cientista é avaliado pelo número de suas publicações. Quanto mais publicações, mais ele é reconhecido, mais facilmente conseguirá aprovar seus projetos em órgãos de fomento. Uma vez que o tema patente ainda é uma espécie de tabu para alguns pesquisadores, eles se desculpam alegando que patente é muito complicada e demorada, além de cara. Por outro lado, a publicação de artigos científicos é gratuita e rápida. Enquanto a publicação do artigo leva, no máximo, um ano para sair, a concessão da patente leva cerca de cinco a seis anos, dependendo da área tecnológica.

Federman (2009) alerta para o perigo da opção pela publicação científica antes do depósito da patente, nos casos em que os resultados da pesquisa tiverem potencial tecnológico: se fizer o depósito da patente e uma empresa se interessar por ela, o pesquisador continuará tendo direito 
sobre sua invenção; se optar por publicar antes e não depositar a patente, correrá o risco de ter sua invenção depositada por alguma empresa que passará a ser sua legítima proprietária. Em sua opinião, o pesquisador deveria primeiro depositar a patente e, depois de concedida, publicar seus artigos.

O pesquisador acadêmico foi educado para ter como objetivo primordial descobrir "a verdade" sobre a realidade e avançar nosso entendimento sobre as coisas. Foi treinado para expor os resultados de suas pesquisas ao crivo dos pares, por meio da publicação referendada, a se esforçar para ganhar os "prêmios da ciência", isto é, o prestígio de ser o primeiro a fazer uma nova descoberta. A pesquisa que visa à inovação patenteável exige um comportamento bem diverso. A meta é descobrir algo útil, que será submetido não exatamente aos pares, mas aos técnicos de um organismo oficial não parte da comunidade científica, exige sigilo e proíbe a publicação aberta e o prêmio virá pela cobrança das licenças concedidas, não necessariamente prestígio acadêmico. É uma nova realidade.

\subsection{Universidades como produtoras de patentes}

Com a mudança de posição em relação à incompatibilidade entre ciência pura e aplicada e a aceitação crescente da responsabilidade do cientista pela solução de problemas sociais e econômicos, a produção de inovações comerciáveis, como resultados de pesquisa acadêmica, também se tornou um fato em vários países. De acordo com Chaves (2009), a universidade começou a ser vista como uma instituição importante na geração de inovação tecnológica. Paralelamente, estudos teóricos para explicar ou modelar esse papel da universidade e sua relação com empresas e o governo começaram a aparecer na literatura. Chaves (2009, p. 19) resume as três principais teorias: o modelo triangular de Sábato, datado da década de 1970, "segundo o qual o Estado é o actor privilegiado", a proposta de Lundvall, apresentada em 1992 e complementada por Nelson em 1993, conhecida como teoria dos sistemas nacionais de inovação, "que considera a empresa como tendo o papel principal no processo de inovação", e a tese da tripla hélice de Etzkowitz e Leydesdorff, no final da década de 1990, que defende um papel cada vez mais relevante para a universidade, "no contexto de sociedades baseadas no conhecimento". Em resumo, os modelos têm em comum a relação entre os três atores, universidade, empresa e governo, mas diferem nos pesos atribuídos a cada ator.

O fato é que mais e mais os governos investem nas universidades como produtoras de inovação. A aprovação do Bayh-Dole Act, em 1980, nos Estados Unidos, "que buscou incentivar a comercialização de descobertas acadêmicas, ao facilitar o processo de obtenção de patentes resultantes de pesquisas financiadas por fundos federais e sua comercialização por parte das universidades" (PÓVOA, 2008, p. 233), inspirou países europeus a fomentarem a pesquisa acadêmica com finalidades práticas. De acordo com Mowery e Sampat (2005, citado por 
CHAVES, 2009), "países membros da OCDE tentaram replicar políticas semelhantes ao Bayh-Dole Act, cujo objectivo consistia em produzir resultados financeiros da investigação académica".

O Brasil não ficou de fora desse movimento, aprovando leis, citadas no início deste texto, para facilitar a transferência de tecnologia entre universidades e empresas, especialmente a Lei de Inovação. Castro e Souza (2012, p. 127-128) comentam sobre o efeito dessa Lei, que traz dispositivos para motivar parcerias entre universidades e empresas e que definiu "as regras quanto à participação dos criadores da tecnologia nos ganhos econômicos gerados pela proteção de propriedade intelectual". Mas, talvez, o maior efeito prático da Lei, segundo esses autores, tenha sido a instalação dos Núcleos de Inovação Tecnológica (NITs) como um órgão da universidade, a um requisito disposto na Lei. Esses NITs são responsáveis pela gestão da política de inovação da universidade, "pela avaliação de suas atividades de pesquisa, assim como pelo acompanhamento do processo de transformação da criação em inovação tecnológica, promovendo e gerenciando parcerias entre universidade e empresas" (CASTRO; SOUZA, 2012, p. 127-128). Esses autores observam, ainda, que a criação dos NITs contribuiu para 0 desenvolvimento e amadurecimento das atividades de inovação nas universidades, mesmo naquelas que já contavam com agências de transferência de tecnologia. Querido (2011, p. 85) realizou levantamento do número de concessões de patentes às universidades e verificou que "se destacaram as universidades que dentre outras características, também eram detentoras dos NITs melhor estruturados".

Como consequência da Lei da Inovação, as universidades e outras instituições de pesquisa em todo o país criaram, em 2006, um Fórum de Gestores de Inovação e Transferência de Tecnologia (FORTEC), agregando, em 2012, 156 NITs. No entanto, segundo Castro e Souza (2012), esses núcleos ainda não se consideram totalmente aceitos por pesquisadores, alunos, inventores e empresas como legítimos gestores e intermediários das atividades relacionadas à divulgação de inovações.

Além dos NITs, Torkomian (2011, p. 2) cita a criação de incubadoras de empresas e parques tecnológicos, como iniciativas da universidade que contribuem para a geração de patentes por seus pesquisadores, inclusive a criação de spin-offs acadêmicos, que são "empresas concebidas para explorar comercialmente resultados da pesquisa acadêmica". Ainda de acordo com Torkomian (2011), o Ministério da Ciência e Tecnologia (MCT) tem interesse no desenvolvimento de parques tecnológicos e incubadoras de empresas de elevado conteúdo tecnológico nas universidades e, para apoiá-los, criou o Programa Nacional de Apoio às Incubadoras de Empresas e Parques Tecnológicos (PNI). De acordo com Torkomian (2011), o PNI define

incubadoras de empresas [como] mecanismos de estímulo e apoio logístico, gerencial e tecnológico ao empreendedorismo inovador e intensivo em conhecimento, que visam facilitar a implantação de novas empresas que tenham como principal 
estratégia de negócio a inovação tecnológica. [...] Parques tecnológicos são complexos de desenvolvimento econômico e tecnológico que visam fomentar e promover sinergias nas atividades de pesquisa científica, tecnológica e de inovação entre as empresas e instituições científicas e tecnológicas, públicas e privadas, com forte apoio institucional e financeiro entre os governos federal, estadual e municipal, comunidade local e setor privado (TORKOMIAN, 2011, p. 2).

Dado esse esforço pelo governo e pelas universidades visando à produção de patentes, foi considerado interessante levantar a produção de patentes universitárias ao longo do tempo, no país. Foi feita busca na literatura por textos que informassem sobre essa produção. Mas essa busca mostrou-se difícil, com resultados fragmentados e, às vezes, conflitantes, cujas bases temporais e geográficas não permitem uma visão consolidada. Nem sempre fica claro se os dados se referem a pedidos de patentes ou concessões. Ainda assim, foi feito um esforço para perceber a evolução, relatada a seguir.

Dados divulgados pela revista digital Em Discussão, do Senado Federal (PATENTES, 2012), mas cuja fonte é PCT Yearly Review, uma publicação da OMPI, mostram o baixo desempenho do Brasil em relação a outros países em pedidos de patentes por residentes (no caso do Brasil, registrados no INPI) e mostram, também, a divisão dos depósitos segundo tipo de depositante: universidades, governo, indivíduos ou empresas. De acordo com essa fonte, empresas foram as maiores depositantes no maior número de países, inclusive no Brasil, onde teriam sido responsáveis por $53,9 \%$ do total depositado em 2012 . Outra fonte informa que, em 2012, o INPI concedeu 3.137 patentes, volume considerado baixo, especialmente se comparado à produção brasileira de artigos científicos, que coloca o Brasil no $13^{\circ}$ lugar entre os países em número de artigos indexados pela Thomson Reuters, em 2009 (THIMOTEO, 2013).

Mas outras fontes trazem dados que contrastam com a informação do PCT Yearly Review ou pelo menos mostram uma situação diferente em anos anteriores. Talvez haja, também, uma diferença quanto aos dados, pois não fica claro quando os autores se referem a patentes concedidas ou solicitações de patentes, ou ambos. Dagnino e Silva (2009) afirmam que entre 2001 e 2008, as universidades públicas brasileiras teriam solicitado 1.359 patentes, enquanto as empresas teriam solicitado apenas 933 . Interessante notar que, na opinião desses autores, a política brasileira de incentivo às universidades para que gerem patentes estaria equivocada. Tomando como exemplo os Estados Unidos, onde a "participação das patentes universitárias no total - cerca de 3\% - é quase insignificante" e afirmando que o mesmo acontece em outros países desenvolvidos, concluem que "é inerente ao bom funcionamento do capitalismo o fato das universidades não gerarem patentes" (DAGNINO; SILVA, 2009, p. 17). 
A data de depósito de patente universitária mais antiga foi encontrada em Póvoa (2008). Este autor construiu um gráfico com base em dados do INPI, mostrando a evolução dos depósitos de patentes universitárias entre em 1979, ano no qual está registrado apenas um depósito, até 2004, com 190 depósitos (PÓVOA, 2008, p. 45). Somados os dados anuais informados por Póvoa, seriam 1.165 patentes ou solicitações entre 1979 e 2004. O mais interessante, no entanto, é a subida abrupta da curva, de 49 patentes registradas em 1999, para 77 e 88 patentes nos dois anos seguintes, e dai para 173, 186 e 190 patentes, para os anos de 2002, 2003 e 2004, respectivamente. Nesse período, estava em discussão, mas não aprovada ainda, a Lei da Invenção de 2004, o que sugere alguma conexão.

Para a década de 1990, o estudo mais citado é o de Assumpção (2000), que relata ter identificado o total de 355 pedidos de patentes depositados nas bases do INPI entre 1990 e 1999, por universidades e outras instituições brasileiras de ensino superior. Os dados de Assumpção mostram crescimento quase contínuo ao longo da década. Estendendo o período estudado por Assumpção (2000), Garnica (2007) reproduz um gráfico publicado por Theotonio, construído com dados do INPI, segundo o qual o número de solicitações de patentes universitárias continuou a subir entre 2000 e 2004 (portanto confirmando Póvoa, 2008), somando nesses quatro anos, 401 pedidos de patentes. Nunes e Oliveira (2007 apud QUERIDO 2011) constataram um aumento ainda maior, de $120 \%$ no número de depósitos efetuados pelas universidades entre os períodos de 2000 a 2004 e a década de 1990.

O crescimento de depósitos de pedidos de patentes universitárias entre a década de 1990 e a primeira década deste Século XXI, é consenso entre os autores lidos, embora os números apresentados nem sempre sejam os mesmos. Mas um exame mais detalhado mostra que esse aumento não é bem distribuído entre as universidades. A criação dos NITs nas universidades como uma exigência da Lei de Inovação teria tido como motivação criar condições adequadas para gestão do conhecimento patenteável, dado o despreparo de muitas delas em lidar com burocracia do INPI e com comercialização. Mas os NITs têm tido diferentes desempenhos. Querido (2011) mostrou, em sua tese, que, das universidades estudadas (amostra incluiu 37 NITs, data 2009), apenas um NIT foi responsável por $50,97 \%$ dos depósitos e $79,4 \%$ dos NITs possuíam um pequeno número de depósitos (p. 66 e 87). Esse autor correlaciona a boa estrutura do NIT com produção mais relevante. Póvoa (2010, p. 245) corrobora, informando que "na lista dos 50 maiores depositantes de patentes no Brasil, entre 1999 e 2003, com prioridade brasileira, aparecem oito universidades (Unicamp, UFMG, USP, UFRJ, Unesp, UFRGS, UFPE e UFV) [...]. Além disso, o primeiro lugar nessa lista é ocupado por uma universidade (Unicamp).

Outros estudos com abrangência regional confirmam a concentração de produção de depósitos na Região Sudeste e, mais especialmente, nas universidades públicas do Estado de São Paulo. Talvez por isso, essas universidades tenham recebido mais atenção dos pesquisadores que 
estudam o tema. Como exemplo, veja-se um estudo conduzido e publicado pela UFRGS, em 2001, mostrando que em 2001, cinco universidades: UNICAMP, UFRJ, UFMG, UFV e USP foram responsáveis por 268 pedidos de patentes e tinham, entre elas, 109 patentes já concedidas, somando o total de 377 entre pedidos e patentes publicadas (apud CHAGAS, 2004 p. 9). Amadei e Torkomian (2009) levantaram pedidos de patentes feitos entre 1995 e 2006 pelas universidades públicas de São Paulo, UNICAMP, USP, UNESP, UFSCar e UFSP, encontrando 672 depósitos. Esses autores confirmam a liderança da UNICAMP, informando que esta universidade foi responsável por $60 \%$ dos pedidos publicados em 2009. Outros estudos, na mesma linha, incluem Garnica e Torkomian (2009), Oliveira e Velho (2009a), Garnica (2007), Pavanelli e Oliveira (2010; 2012) e Oliveira (2011). Outros estudos concentram sua atenção em única universidade, como é o caso de Garnica, Oliveira e Torkomian (2006), sobre a UFSCar; Pavanelli e Oliveira (2012) sobre a UNESP; e Castro; Jannuzzi e Mattos (2007) sobre a INOVA da Unicamp, todas situadas no Estado de São Paulo.

A região nordeste foi estudada por Serafini et al. (2011), que fizeram busca em três bases: European Patent Office - Espacenet; base da OMPI; e Banco de dados do INPI, nas quais identificaram depósitos feitos por universidades dos nove estados daquela região. Verificaram que a maioria desses depósitos foi feito no INPI, o que seria esperado, por ser a base brasileira, e que Pernambuco foi o estado cujas universidades mais patentearam. Os autores constataram que os depósitos aumentaram em volume a partir de 2005, portanto, logo após a promulgação da Lei da Invenção, em 2004. Verificaram, também, que as patentes relacionadas às áreas de química e metalurgia ( $C$ na classificação CIP) foram as mais frequentes.

Estudos sobre as demais regiões do país não foram encontrados, mas essas regiões são, às vezes, tratadas em estudos de abrangência nacional, como, por exemplo: Souza, Barbastefano e Pereira (2001), sobre o perfil de professores/inventores de documentos de patentes depositadas no INPI; Pinheiro-Machado e Oliveira (2004), que comparam pedidos de patentes de universidades e institutos de pesquisa públicos no INPI com pedidos de patentes das universidades americanas no USPTO; e Perucchi e Mueller (2012), que verificaram a produção de patentes pelos Institutos Federais de Educação, Ciência e Tecnologia.

O que transparece dessas leituras é o interesse crescente do governo nas universidades como produtoras de inovação e, ao mesmo tempo, diferenças muito grandes entre essas instituições, na capacidade de gerar patentes. Fica clara também a necessidade de dados mais exatos sobre a produção de patentes. 


\subsection{Gestão da produção e comercialização das patentes universitárias}

O fato de um pedido de patente ser depositado não significa que a patente será concedida. E o fato da patente ser concedida não significa que ela venha a ser licenciada para algum interessado ou venha a ser explorada de alguma maneira. Thimoteo (2013 p. 45), em matéria especial sobre inovação publicada na Revista Conjuntura Econômica informa que "de acordo com o Inpi (sic), 15 mil pedidos de patentes são analisados a cada ano, mas apenas $30 \%$ dos depositantes conseguem registros". Todo o processo é longo e difícil e pode ser custoso. O prazo médio entre solicitação e resposta, que pode ser favorável ou não à concessão da carta-patente, é de 10 anos, muito mais longo que em países desenvolvidos. Neste mesmo artigo, Thimoteo (2013, p. 44) relata dois casos de pesquisadores ligados a universidades públicas, que registraram pedidos de patentes para a mesma inovação no INPI e no equivalente americano UPSTO. Depois de algum tempo (mais longo para um deles), receberam a patente americana, mas, até maio de 2013, ainda estavam sem resposta do INPI. Para tornar mais eficiente esse processo, - INPI anunciou a modernização do processamento, por meio da plataforma de depósito online de patentes, a e-Patente, lançada em março de $2013^{4}$. Entre março 2013, mês do lançamento e abril do mesmo ano, teria havido um aumento de cerca de 15 para cerca de 85 depósitos nacionais (THIMOTEO, 2013, p. 43).

O valor da patente é outra questão de interesse. De acordo com o boletim eletrônico do Instituto Nacional de Propriedade Industrial de Portugal, INPIonline (PORTUGAL, [s.d.]), essa é uma pergunta difícil de responder, pois depende do potencial de comercialização ou exploração econômica que a patente apresenta. Segundo essa fonte portuguesa, há três formas de atribuir valor e comercializar a patente: "pela incorporação da patente no negócio do seu titular, ou seja, pela exploração directa da patente pelo seu proprietário; através da venda da patente ou, finalmente, pelo licenciamento dos direitos de exploração da patente a terceiros". Considerando pesquisadores/inventores acadêmicos, fica clara a dificuldade por eles enfrentada para comercializar ou licenciar suas patentes. Para isso, nas universidades brasileiras foram criados os NITs.

Os NITs são encarregados do gerenciamento da política adotada pela universidade em relação à inovação, responsabilidade que inclui todo o processo, da solicitação de depósito ao licenciamento. Caberia aos NITs orientar os professores/inventores quanto às possibilidades de patenteamento e de assumir algumas das inciativas necessárias para o andamento da solicitação e comercialização. Mas nem sempre os NITs têm cumprido essa missão com sucesso. A tese desenvolvida por Querido (2011), já citada, intitulada Destino das patentes das universidades brasileiras e mapeamento das atividades dos Núcleos de Inovação

4 Disponível em: <http://epatentes.inpi.gov.br/modulo2/edeposito/>. Acesso em: 10 maio 2013. 
Tecnológica, verificou que, até a data em que coletou seus dados, "65\% dos NITs ainda não [possuíam] licenciamento e mesmo NITs com um número significativo de patentes nunca comercializaram suas tecnologias". Seus dados mostram, ainda, que a universidade de sua amostra que mais havia depositado, total de 491 patentes, havia licenciado apenas 55, portanto $11,20 \%$. Constatou que em universidades nas quais os NITs apresentaram gerenciamento falho ou desestruturado, havia "um grande número de abandonos de pedidos, por perda de prazos de agendamentos (anuidades) com posterior arquivamento, evidenciando falta de estrutura no gerenciamento do processo" (QUERIDO, 2011, p. 85).

O papel dos NITs nas universidades é de importância estratégica, especialmente quando se considera que a experiência dos professores e pesquisadores está muito mais ligada à pesquisa do que à administração e que muitos foram educados considerando a ciência como conhecimento público e não bem comercial. A gestão da informação parece ter um lugar relevante nesse cenário.

\section{Comentários finais}

Neste Século XXI, parece ter se consolidado a ideia da universidade como produtora ativa de conhecimento patenteável. O estudo do fluxo desse tipo de conhecimento e das questões de informação a ele relacionadas representa um desafio para profissionais e estudiosos da informação, cuja atenção tem sido tradicionalmente dirigida para informação científica. O argumento deste texto é que existem fatores presentes no ambiente onde são geradas e gerenciadas as patentes universitárias que não podem deixar de ser consideradas em estudos sobre esse tema, conduzidos sob a ótica da ciência da informação, porque são potencialmente influentes no objeto de estudo. Ignorá-los ou negligenciá-los poderia tornar a pesquisa irrelevante.

O levantamento na literatura revelou, dentre outros, três tópicos recorrentes, que foram selecionados para exposição e discussão. Primeiro, foram expostos fatores que afetam o pesquisador/inventor, especialmente os dilemas decorrentes de mudanças ideológicas e econômicas, que agora pressionam ou motivam o pesquisador a comportamentos distintos do estabelecido pela tradição acadêmica. Depois, foram apresentados dados que revelaram acentuadas desigualdades na capacidade de produzir patentes entre as universidades públicas brasileiras, mostrando a concentração da produção em poucas universidades da Região Sudeste. Provavelmente essa concentração reflete a desigualdade que há em vários aspectos das universidades, não apenas na produção de patentes. Os textos lidos revelaram, também, inadequação de muitas universidades na capacidade de gerência, mesmo com a criação dos NITs. Esses pontos, especialmente se somados a outros como os mencionados mais abaixo, devem formar um pano de fundo no planejamento de pesquisas, que têm entre seus objetivos a comunicação tecnológica e como pressuposto a patente universitária, como um veículo dessa informação. Nos planos de 
pesquisa qualitativa, estariam refletidos, por exemplo, nas questões submetidas a respondentes e na interpretação dos resultados. Nas pesquisas quantitativas, contribuiriam para definir a estratégia de coleta de dados e para a discussão dos resultados.

O tema abordado neste texto é complexo e as informações levantadas apenas esboçam alguns dos muitos fatores presentes no contexto da geração e gestão das patentes acadêmicas. Vários outros tópicos, igualmente influentes nos estudos sobre comunicação da informação tecnológica, relacionados com a patente universitária, poderiam ter sido incluídos, por exemplo, questões ligadas aos contratos de transferência de tecnologia ou licenciamento para o setor produtivo e a participação do pesquisador/inventor nos recursos pecuniários advindos da comercialização, transferência ou licenciamentos de tecnologia; questões ligadas às políticas governamentais de incentivo à geração de patentes pelas universidades e aos aspectos jurídicos que afetam 0 processo, que aqui foram apenas mencionadas. $\mathrm{E}$, em um nível teórico, seria proveitoso explorar os diversos modelos que tentam explicar 0 relacionamento governo/empresa/universidade como um dado nos estudos da patente como veículo de informação.

A pretensão deste texto foi contribuir para as pesquisas em ciência da informação, apontando fatores potencialmente influentes no contexto no qual a patente universitária é gerada e gerenciada e espera-se que os pontos apresentados motivem estudos mais aprofundados. A gerência de patentes é de importância estratégica para as universidades modernas e, também, para o País. Houve uma mudança profunda e rápida no papel da ciência frente à sociedade, que hoje espera muito mais dos investimentos públicos em pesquisas. Por outro lado, as nações, ao mesmo tempo em que cooperam entre si, também competem de maneira acirrada e precisam resguardar suas descobertas. Parece haver aí um campo fértil para pesquisas e serviços na área de informação.

\section{Referências}

AGÊNCIA USP de Inovação. Patentes. 2013. Disponível em: <www.inovacao.usp.br/propriedade/patentes.php>. Acesso em: 18 abr. 2013.

AMADEI, J. R. P.; TORKOMIAN, A. L. V. As patentes nas universidades: análise dos depósitos das universidades públicas paulistas. Ciência da Informação, Brasília, v. 38, n. 2, p. 9-18, maio/ago. 2009. Disponível em: $<$ http://revista.ibict.br/ciinf/index.php/ciinf/article/view/1054/>. Acesso em: 14 jun. 2012.

ASSUMPÇÃO, E. A utilização do sistema de patentes pelas universidades brasileiras nos anos 90. Rio de janeiro: INPI, 2000.

BRASIL. Lei $n^{\circ}$ 9.279, de 14 de maio de 1996. Regula direitos e obrigações relativos à propriedade industrial. Diário Oficial da União, 15 de maio de 1996, p. 8353. Disponível em: <http://www.planalto.gov.br/ccivil 03/leis/L9279.htm>. Acesso em: 16 jul. 2012. 
BRASIL. Lei no 10.973, de 2 de Dezembro de 2004. Dispõe sobre incentivos à inovação e à pesquisa científica e tecnológica no ambiente produtivo e dá outras providências. Diário Oficial da União, 3 de dezembro de 2004, p. 2. Disponível em: <http://www2.camara.gov.br/legin/fed/lei/2004/lei10973-2-dezembro-2004-534975-publicacaooriginal-21531-pl.html>. Acesso em: 16 jul. 2012.

CASTRO, A. C.; JANNUZZI, C. A. S. C.; MATTOS, F. A. M. de. Produção e disseminação de informação tecnológica: a atuação da Inova - Agência de Inovação da UNICAMP. Transinformação, Campinas, v. 19, n. 3, p. 265277, set./dez. 2007. Disponível em:

<http://revistas.puc-campinas.edu.br/transinfo/viewissue.php>. Acesso em: 28 set. 2012.

CASTRO. B. S.; SOUZA, G. C. de. O papel dos Núcleos de Inovação Tecnológica (NITs) nas universidades brasileiras. Liinc em Revista, v.8, n.1, p. 125-140, mar. 2012. Disponível em: $<$ http://revista.ibict.br/liinc/index.php/liinc/article/viewFile/465/360>. Acesso em: 17 maio 2013.

CHAGAS, E. Apreensão, implementação e gestão da propriedade intelectual nas instituições públicas de ensino superior. 2004. 152f. Tese (Doutorado em Extensão Rural) - Universidade Federal de Viçosa, Viçosa, 2004. Disponível em: <htpp://www.alexandria.cpd.ufv.br:8000/teses/extensao\%20rural>. Acesso em: 22 jun. 2012.

CHAVES, D. C. R. A universidade empreendedora do séc. XXI: o papel estratégico da propriedade industrial. 2009. 135f. Dissertação (Mestrado em Sociologia) - Faculdade de Economia da Universidade de Coimbra, 2009.

DAGNINO, R.; SILVA, R. B. da. As patentes das universidades públicas. Economia \& Tecnologia, v. 5, n. 18, p. 169-172, jul./set. 2009. Disponível em

<http://www.economiaetecnologia.ufpr.br/boletim/Economia \& Tecnologia Ano 05 Vol 018.pdf>. Acesso em: 19 maio 2013.

FEDERMAN, S. R. Publicar ou depositar a patente. Boletim da UFMG, v. 36, n. 1669, 2009. Disponível em: <https://www.ufmg.br/boletim/bol1669/2.shtml>. Acesso em: 23 abr. 2013.

FRANÇA, R. O. A patente. In: CAMPELLO, B. S; CENDÓN, B. V.; KREMER, J. M. (Orgs.). Fontes de informação para pesquisadores e profissionais. Belo Horizonte: Editora UFMG, 2000. cap.12, p.152-182.

GARNICA, L. A. Transferência de tecnologia e gestão da propriedade intelectual em universidades públicas no estado de São Paulo. 2007. 206f. Dissertação (Mestrado em Engenharia de Produção) - Centro de Ciências Exatas e de Tecnologia, Universidade Federal de São Carlos, São Carlos, 2007. Disponível em: <http://www.sel.eesc.usp.br/transferencia de tecnologia>. Acesso em: 22 jun. 2012. 
GARNICA, L. A.; TORKOMIAN, A. L. V. Gestão de tecnologia em universidades: uma análise do patenteamento e dos fatores de dificuldade e de apoio à transferência de tecnologia no Estado de São Paulo. Gest. Prod., São Carlos, v. 16, n. 4, p. 624-638, out./dez. 2009. Disponível em: <http://www.scielo.br/scielo.php?script=sci_arttext\&pid=S0104$530 \times 2009000400011 \&$ Ing =en\&nrm=iso $>$. Acesso em: 16 maio 2013.

GARNICA, L. A.; OLIVEIRA, R. M. de; TORKOMIAN, A. L. V. Propriedade intelectual e titularidade de patentes universitárias: um estudo piloto na Universidade Federal de São Carlos - UFSCar. In: SIMPÓSIO DE GESTÃO E INOVAÇÃO TECNOLÓGICA, 24., 2006, Gramado, RS. Anais... Gramado, RS., 2006.2 Disponível em: <http://www.anpad.org.br/diversos/trabalhos/Simp\%C3\%B3sio/simposio 2006/DCT/ DCT456.pdf $>$. Acesso em: 22 abr. 2013.

GRUPO MERCOSUL MARCAS E PATENTES. Patentes: uma breve introdução. c19952005. Disponível em: <http://www.grupomercosul.com.br/patentes.htm>. Acesso em: 27 maio 2013.

HANSON, C. W. Subject inquiries and literature searching. In: BATTEN, E. E. (Org.). Handbook of special librarianship and information work. 4. ed. London: ASLIB; Billing \& Sons, 1975. p. 299-319.

INSTITUTO NACIONAL DA PROPRIEDADE INDUSTRIAL - INPI. Conheça o INPI. CGCOM. 28 dez. 2012. Disponível em: <http://www.inpi.gov.br/portal/artigo/conheca o inpi>. Acesso em: 21 abr. 2013.

INSTITUTO NACIONAL DA PROPRIEDADE INDUSTRIAL - INPI. Guia básico: patentes. 2013. Disponível em: $<$ http://www.inpi.gov.br/portal/artigo/guia basico patentes $>$. Acesso em 27 abr. 2013.

INTERNATIONAL PATENT CLASSIFICATION GUIDE: version 2013. 2013. Disponível em: <http://www.wipo.int/export/sites/www/classifications/ipc/en/guide/guide ipc.pdf>. Acesso em: 2 maio 2013

JANNUZZI, A. H. L.; AMORIM, R. de C. R.; SOUZA, C. G. de. Implicações da categorização e indexação na recuperação da informação tecnológica contida em documentos de patentes. Ci. Inf., Brasília, v. 36, n. 2, p. 2734, maio./ago. 2007. Disponível em: http://revista.ibict.br/ciinf/index.php/ciinf/article/view/976/716. Acesso em: 3 jun. 2013.

LAMANA, S.; KOVALESKI, J. L. Patentes e o desenvolvimento econômico. In: CONVIBRA ADMINISTRAÇÃO - CONGRESSO VIRTUAL BRASILEIRO DE ADMINISTRAÇÃO, $7.2010 . \quad$ Disponível em: <http://www.convibra.com.br/upload/paper/adm/adm 1518.pdf>. Acesso em: 22 abr. 2013.

McMILLAN, S. et al. The ethical dilemma of research and development openness versus secrecy. Journal of Business Ethics, v. 65, n. 3, p. 279- 
285, 2006. Disponível em: <http://link.springer.com/article/10.1007\%2Fs10551005-5495-0 >. Acesso em: dia maio 2013.

MOWERY, D. C.; SAMPAT, B. N. Universititis in National Innovation Systems. In: FARGERBERG, J.; MOWERY, D.; NELSON, R. (Orgs.). The Oxford Handbook of Innovation. Oxford: University Press, 2005. p. 209239 apud CHAVES, D. C. R. A universidade empreendedora do séc. XXI: o papel estratégico da propriedade industrial. 2009. 135f. Dissertação (Mestrado em Sociologia) - Faculdade de Economia da Universidade de Coimbra, 2009.

NUNES, J. S.; OLIVEIRA, L. G. Universidades brasileiras: utilização do sistema de patentes de 2004 a 2008. Instituto Nacional de Propriedade Industrial - Centro de Documentação e Informação Tecnológica. 2007. Disponível em: http://www.inpi.gov.br/menuesquerdo/informação/estudos_html. Acesso: 23 março de 2010 apud QUERIDO, A. L. S. Destino das patentes das universidades brasileiras e mapeamento das atividades dos Núcleos de Inovação Tecnológica. Rio de Janeiro, 2011. 147f. Tese (Doutorado em Biotecnologia Vegetal) - Centro de Ciências da Saúde - Universidade Federal do Rio de Janeiro, Rio de Janeiro, $2011 . \quad$ Disponível em: <http://fenix3.ufri.br/50/teses/d/CCS D AndreLuizDeSouzaQuerido.pdf>. Acesso em: 19 maio 2013.

OLIVEIRA, R. M. de. Proteção e comercialização da pesquisa acadêmica no Brasil: motivações e percepções dos inventores. 2011. 187f. Tese (Doutorado em Política Científica e Tecnológica) - Instituto de Geociências, Universidade Estadual de Campinas, Campinas, 2011. Disponível em: <http://www.bibliotecadigital.unicamp.br/document>. Acesso em: 22 jun. 2012.

OLIVEIRA, R. M. de; VELHO, L. M. L. S. Patentes acadêmicas no Brasil: uma análise sobre as universidades públicas paulistas e seus inventores. Parcerias Estratégicas, Brasília, v. 14, n. 29, p. 173-200, jul./dez, 2009a. Disponível em: <http://seer.cgee.org.br/index.php/parcerias estrategicas/article>. Acesso em: 14 jun. 2012.

OLIVEIRA, R. M. de; VELHO, L. M. L. S. Benefícios e riscos da proteção e comercialização da pesquisa acadêmica: uma discussão necessária. Ensaio: aval. pol. públ. Educ., Rio de Janeiro, v. 17, n. 62, p. 25-54, jan./mar. 2009b. Disponível em: $<$ http://www.scielo.br/scielo.php?script=sci arttext\&pid=S010440362009000100003>. Acesso em: 28 set. 2012.

PATENTES, calcanhar de Aquiles. Em Discussão! Revista de audiências públicas do Senado Federal, v. 3, n. 12, p. 60-61, set. 2012. Disponível em:

$<$ http://www.senado.gov.br/noticias/Jornal/emdiscussao/inovacao/univer sidades-brasil-doutores-pesquisas-patentes-inovacao-tecnologica/numerode-patentes-por-empresas-ou-pesquisadores-em-universidades-e-baixono-brasil.aspx>. Acesso em: 23 abr. 2013. 
PAVANELLI, M. A.; OLIVEIRA, E. F. T. de. Análise das patentes registradas no âmbito da Universidade Estadual Paulista: primeiras aproximações. In: ENCONTRO NACIONAL DE PESQUISA EM CIÊNCIA DA INFORMAÇÃO, 11., 2010, Rio de Janeiro. Anais... Rio de Janeiro: IBICT, 2010. Disponível em: $<$ http://repositorios.questoesemrede.uff.br/repositorios/bitstream/handle 123456789/1915/An\%c3\%a1lise\%20-\%20Pavanelli.pdf?sequence=1 > .

Acesso em: 12 abr. 2012. Pôster-

PAVANELLI, M. A.; OLIVEIRA, E. F. T. de. Estudo patentométrico na Universidade Estadual Paulista. In: ENCONTRO NACIONAL DE PESQUISA EM CIÊNCIA DA INFORMAÇÃO, 13., 2012, Rio de Janeiro. Anais... Rio de Janeiro: $\quad 2012 . \quad$ DIOCRUZ, 2 emonível $<$ http://repositorios.questoesemrede.uff.br/repositorios/bitstream/handle 123456789/1971/Pavanelli Estudo.pdf?sequence=1 >. Acesso em: 25 out. 2012.

PERUCCHI, V.; MUELLER, S. P. M. Patentes produzidas pelos Institutos Federais de Educação, Ciência e Tecnologia. In: WORKSHOP INTERNACIONAL EM CIÊNCIA DA INFORMAÇÃO, 8., 2012, Brasília. Anais... Brasília: UnB, 2012. Pôster.

PINHEIRO-MACHADO, R.; OLIVEIRA, P. L. A comparative study of patenting activity in U.S. and Brazilian scientific institutions. Scientometrics, v. 61, n. 3, p. 323-338, 2004.

PORTUGAL. INSTITUTO NACIONAL DA PROPRIEDADE INDUSTRIAL. Valorização da PI. INPIonline, s.d. Disponível em: $<$ http://www.marcasepatentes.pt/index.php?section=366>. Acesso em: 3 jun. 2013.

PÓVOA, L. M. C. Patentes de universidades e institutos públicos de pesquisa e a transferência de tecnologia para empresas no Brasil. 2008. 153f. Tese (Doutorado em Economia) - Centro de Desenvolvimento e Planejamento Regional, Faculdade de Ciências Econômicas, Universidade Federal de Minas Gerais, Belo Horizonte, 2008. Disponível em: <http://www.bibliotecadigital.ufmg.br/dspace/handle/1843>. Acesso em: 22 jun. 2012.

PÓVOA, L. M. C. A universidade deve patentear suas invenções? Revista Brasileira de Inovação, Rio de Janeiro, v. 9, n. 2, p. 231-256, jul./dez. 2010. Disponível em: <http://www.ige.unicamp.br/ojs/index.php/rbi/article/view/474>. Acesso em: 28 set. 2012 .

QUERIDO, A. L. S. Destino das patentes das universidades brasileiras e mapeamento das atividades dos Núcleos de Inovação Tecnológica. Rio de Janeiro, 2011. 147f. Tese (Doutorado em Biotecnologia Vegetal) - Centro de Ciências da Saúde - Universidade Federal do Rio de Janeiro, Rio de Janeiro, 2011. Disponível em: $<$ http://fenix3.ufri.br/50/teses/d/CCS D AndreLuizDeSouzaQuerido.pdf>. Acesso em: 19 maio 2013. 
ROSENBERG, N. Critical issues in science policy and research. Science and Public Policy, v. 18, p. 335, Dec. 1991 apud STOKES, D. E. O quadrante de Pasteur: a ciência básica e a inovação tecnológica. Campinas: UNICAMP, 2005.

SERAFINI, M. R. et al. Características da propriedade intelectual no nordeste através de sites de buscas tecnológicas. Revista GEINTEC: gestão, inovação e tecnologias, São Cristóvão/SE, v. 1, n. 1, p. 1-11, 2011.

<http://www.revistageintec.net/portal/index.php/revista/article>. Acesso em: 15 jun. 2012.

SOUZA, C. G. de; BARBASTEFANO, R. G.; PEREIRA, F. de C. Estudo sobre o perfil dos inventores das patentes de universidades brasileiras. In: ENCONTRO NACIONAL DE ENGENHARIA DE PRODUCAO, 31., 2011, Belo Horizonte. Anais... Belo Horizonte: ABREPO, 2011. p. 1-12. Disponível em: <http://www.abepro.org.br/.../enegep2011_TN STO 142.pdf>. Acesso em: 02 jun. 2012.

STOKES, D. E. O quadrante de Pasteur: a ciência básica e a inovação tecnológica. Campinas: UNICAMP, 2005.

THIMOTEO, T. Conhecimento represado. Conjuntura Econômica, v. 67, n. 5, p. 42-45, maio 2013.

TORKOMIAN, A. L. V. Inovação tecnológica e universidade: papel dos parques tecnológicos e incubadoras de empresas. In: SBPC, Reunião Anual, 63., 13 de julho de 2011. Goiânia, Goiás. Anais... [s.l.: s.n.], 2011. Disponível em: $<$ http://www.sbpcnet.org.br/livro/63ra/resumos/PDFs/arq 1428 351.pdf $>$ Acesso em: 3 de junho 2013. 